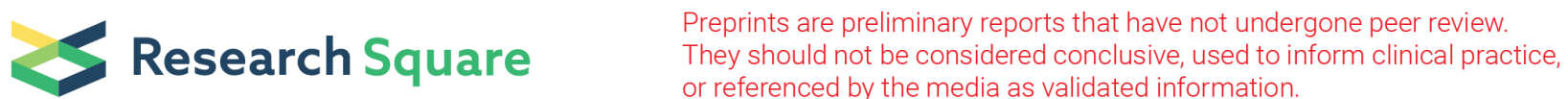

\section{Clinical course and features of critical patients with COVID-19: a single-center, retrospective study from Wuhan Huoshenshan Hospital}

Huisi He

National Center for Liver Cancer Second Military Medical University, Shanghai, China ;Eastern Hepatobiliary Surgery Hospital, Second Military Medical University, Shanghai, China

Zhichao Jin

Department of Health Statistics, Faculty of Medical Service, Second Military Medical University,

Shanghai, China

\section{Yibin Ren}

National Center for Liver Cancer Second Military Medical University, Shanghai, China; Eastern Hepatobiliary Surgery Hospital, Second Military Medical University, Shanghai, China

Junxue Wang

Department of Infection Diseases, Changzheng Hospital, Second Military Medical University, Shanghai, China; Department of Infection Control, Wuhan Huoshenshan Hospital, Wuhan, China

\section{Wen Wen}

National Center for Liver Cancer Second Military Medical University, Shanghai, China ;Eastern Hepatobiliary Surgery Hospital, Second Military Medical University, Shanghai, China

\section{Yushan Miao}

Department of Respiratory and Critical Care Medicine, Changzheng Hospital, Second Military Medical University, Shanghai, China

\section{Xuewei Qi}

National Center for Liver Cancer Second Military Medical University, Shanghai, China; Division of Life Sciences and Medicine, Cancer Research Center, University of Science and Technology of China, Hefei, China

\section{Taiyu Shang}

National Center for Liver Cancer Second Military Medical University, Shanghai, China; Institute of Metabolism and Integrative Biology, Fudan University, Shanghai, China

\section{Chenxu Zhang}

Department of Health Statistics, Faculty of Medical Service, Second Military Medical University, Shanghai, China

\section{Hongyang Wang}

National Center for Liver Cancer Second Military Medical University, Shanghai, China ;Eastern Hepatobiliary Surgery Hospital, Second Military Medical University, Shanghai, China; Ministry of 
Education (MOE) Key Laboratory on Signaling Regulation and Targeting Therapy of Liver Cancer, Second Military Medical University, Shanghai, China

\section{Weiqin Li ( $\nabla$ liweiqindr@vip.163.com )}

Department of Critical Care Medicine, PLA Key Laboratory of Emergency and Critical Care Research, Jinling Hospital, School of Medicine, Nanjing University, Nanjing, China; Department of Critical Care Medicine, Wuhan Huoshenshan Hospital, Wuhan, China

\section{Xijing Zhang ( $\sim$ zhangxj918@163.com )}

Department of ICU Center, Xijing Hospital, Forth Military Medical University, Xi'an, China; Department of Critical Care Medicine, Wuhan Huoshenshan Hospital, Wuhan, China

\section{Hao Tang ( $\square$ tanghao_0921@126.com )}

Department of Respiratory and Critical Care Medicine, Changzheng Hospital, Second Military Medical University, Shanghai China; Department of Critical Care Medicine, Wuhan Huoshenshan Hospital, Wuhan, China

\section{Research Article}

Keywords: SARS-CoV-2, coronavirus, transmission, ARDS, pneumonia

Posted Date: April 3rd, 2020

DOI: https://doi.org/10.21203/rs.3.rs-21014/v1

License: (c) (i) This work is licensed under a Creative Commons Attribution 4.0 International License. Read Full License 


\section{Abstract}

Background and Aims: The coronavirus pandemic has become a growing public health concern worldwide, and there are insufficient epidemiological data on critical illness. We sought to investigate the clinical course and features of critical patients with Corona Virus Disease 2019 (COVID-19).

Method: The data on 94 critical patients from $8^{\text {th }}$ February through $16^{\text {th }}$ March 2020 , including demographic and clinical information, were obtained from the intensive care unit (ICU) of Wuhan Huoshenshan Hospital. A cross-sectional survey and comparisons of key biomarkers between survivors and nonsurvivors were performed.

Results: Over the study period, 42 nonsurvivors and 52 survivors were included. The overall case fatality rate for critical patients with COVID-19 was approximately $45 \%$. The average age was $69.17 \pm 9.55$ years, and the majority had underlying health problems such as hypertension (56[60\%]) and diabetes (18[19\%]). The median length of ICU stay was 8 days (IQR 4, 13). Compared with survivors, nonsurvivors were more likely to develop sepsis $(42[100 \%]$ vs. $34[65 \%])$, acute respiratory distress syndrome (40[95\%] vs. $28[54 \%])$ and organ dysfunction. In addition, the dynamic changes in some biomarkers were significantly different between the two groups. The trajectories of temperature revealed that the group with a high temperature on admission that steadily declined had the highest percentage of deaths $(93.33 \%)$.

Conclusion: Patients aged 60 years or older with many concomitant diseases were at highest risk, and the fatality rate started to increase with age. Lymphocyte, platelet, C-reactive protein and hypersensitivity troponin I were revealed to have potential as prognostic factors, whereas some other biomarkers, such as hepatic enzymes, may not offer additional information. Moreover, patients with high temperatures on admission should receive extra care.

\section{Introduction}

A new outbreak of Corona Virus Disease 2019 (COVID-19) occurred in late December 2019 in Wuhan, China, and has spread to other countries with cases doubling within days through person-to-person transmission, which has been confirmed both in and outside of China. ${ }^{1,2}$ As of $1^{\text {st }}$ April or roughly three months into the outbreak, the number of cases of COVID-19 worldwide, except for China, has exceeded 774,703 across 202 countries, and China has confirmed 82,724 cases. ${ }^{3}$ Unfortunately, imported coronavirus infections have surged in China.

According to the World Health Organization (WHO) interim guidelines ${ }^{4}$ and Chinese Clinical Guidance For COVID-19 Pneumonia Diagnosis and Treatment (7th edition) ${ }^{5}$, the confirmed patients are divided into four categories ranging from mild to critical, based on their clinical manifestations. Most recent studies have investigated COVID-19, providing well-rounded, detailed illustrations of the clinical characteristics of infected patients. ${ }^{1,2,6-10}$ However, there are certain drawbacks associated with the sample sizes and study of critically ill patients who require the greatest use of medical sources. These findings indicate an 
urgent need to understand the various perceptions of COVID-19 that exist among patients in critical condition.

In this study, we sought to analyze data from the intensive care unit (ICU) in Wuhan Huoshenshan Hospital to help address these research gaps and provide one of the first comprehensive clinical descriptions of critical patients with COVID-19.

\section{Methods}

\section{Data source and participants}

This was a cross-sectional study focused on critical patients with COVID-19. We included consecutive critically ill patients with COVID-19 registered in the ICU of Wuhan Huoshenshan Hospital, which is an emergency specialty field hospital constructed in response to the COVID-19 outbreak and runs under the management of the People's Liberation Army.

Patients were included if they met the following criteria: 1) primary diagnosis of COVID-19 confirmed by next-generation sequencing or real-time polymerase-chain-reaction methods; and 2) defined as critical based on the need for supportive care with mechanical ventilation or treatment for organ failure.

Informed consent was not obtained from the patients for this study due to the ongoing viral epidemic in mainland China. This study was approved by the Ethics Commission of Wuhan Huoshenshan Hospital.

\section{Procedure}

Demographic and clinical data were retrieved from electronic medical records and nursing records, including age, sex, exposure history, onset symptoms, personal history, underlying health problems, vital signs on admission, baseline laboratory data before treatment (i.e., blood routine, liver function, kidney function, electrolyte levels, coagulation function, cardiac function, procalcitonin [PCT]), dynamic changes in key laboratory indexes (i.e., temperature, white blood cell count [WBC], total lymphocyte count [TLC], platelet [PLT], C-reactive protein [CRP], alanine transaminase [ALT], aspartate transaminase [AST], PCT, total bilirubin [TBIL], hypersensitive troponin I [hsTNI], creatinine [CRE], creatine kinase-MB, B-type natriuretic peptide), length of ICU stay, time from admission to ICU transfer, comorbidities and complications, and treatments. Data collection was completed by three independent authors.

\section{Outcomes}

The primary endpoint of interest was fatality after ICU admission. Among nonsurvivors, patients were transferred out of the ICU were based on the following criteria: 1) extubated and no requirement for mechanical ventilation; 2) stable hemodynamic parameters without vasoactive agents; 3 ) stable respiratory status and airway patency (patients with respiratory rates of less than 30 breaths per minute 
and satisfactory oxygen saturation of more than $95 \%$ by nasal oxygen of $5 \mathrm{~L} / \mathrm{min}$ ); 4) controlled cardiac dysrhythmias; 5) neurologic stability with controlled seizures or delirium; and 6) keeping in above states for more than 48 hours. Those who met the first five of the above criteria but had not yet reached the observation time were stabilized. Those who could be discharged were evaluated according to the Novel Coronavirus Pneumonia Diagnosis and Treatment Plan (provisional, version 7.0). ${ }^{5}$ Additionally, the follow-up was defined as the period from admission into the ICU until 16th March.

The secondary endpoints were diverse laboratory indexes and the incidence of complications. Acute respiratory disease syndrome (ARDS) was recognized based on the Berlin ARDS definition. ${ }^{11}$ Acute kidney injury was diagnosed if CRE increased by $26.5 \mathrm{mmol} / \mathrm{L}$ or more in $48 \mathrm{~h}$ or rose by at least 1.5 -fold from baseline within 7 days. ${ }^{11}$ The diagnosis of gastrointestinal hemorrhage was based on complaints from the patients or aspiration of gastric contents. The term myocardial injury was used when troponin values were elevated above the $99 \%$ upper reference limit. Secondary bacterial infection was detected by symptoms, signs and blood tests (i.e., blood routine, CRP and PCT). The Sequential Organ Failure Assessment (SOFA) score was used to assess the patient's condition to diagnose sepsis (SOFA $\geq 2){ }^{12}$ Coagulopathy was defined as a 3-second extension of the prothrombin time or a 5-second extension of the activated partial thromboplastin time. COVID-19-associated abnormal liver injury was diagnosed if ALT or AST increased to 3-fold over the upper limit or if TBIL was more than twice the upper limit without another cause. $^{13}$

\section{Statistical analysis}

Descriptive statistics were used to tabulate these patients' clinical features; means and standard deviation or median and interquartile ranges (IQR) are reported for continuous variables, and number is reported for categorical variables. Differences between the survivor and non-survivor groups were compared by the $\chi 2$ test, Wilcoxon rank-sum tests and Fisher's exact tests were applied for categorical variables, and t-tests, Wilcoxon rank-sum tests were applied for continuous variables. The distributions were considered significantly different with an $\alpha$ risk of $5 \%$ if the P value was less than 0.05 .

In addition, we adopted a group-based trajectory modeling approach to identify different patterns of temperature from admission to day 28 (temperature was recorded 6 times each day at 2 a.m., 6 a.m., 10 a.m., 2 p.m., 6 p.m. and 10 p.m.). The shapes and optimal number of groups were determined by the following criteria: 1) Bayesian information criterion was highest; 2 ) the number of patients in each group was not less than $10 \%$ of the total; and 3 ) high average posterior probability of assignment $(>0.7)$.

Data management and analysis were performed using Microsoft EXCEL (version 16.35) and SAS software (version 9.4) for Windows.

\section{Results}


Between 8th February and 16th March, 107 patients were admitted to the ICU of Wuhan Huoshenshan Hospital, and 13 patients who did not reach the endpoint were ineligible. The patient flow chart is shown in Figure 1. Ultimately, 94 critical patients met our inclusion criteria and were included in this study. Overall, 42 (45\%) of them eventually died, another 14 (15\%) patients were discharged from our hospital, $30(32 \%)$ patients were transferred out of the ICU, and $8(8 \%)$ were in stable condition.

An overview of the baseline characteristics of nonsurvivors $(n=42)$ and survivors $(n=52)$ in terms of demographic and underlying health problems is provided in Table 1. There were $54(58 \%)$ males and 40 $(43 \%)$ females, and the average age was $69.17 \pm 9.55$ years. We found that most critical patients were over 60 years old, and the average age was significantly higher in nonsurvivors than in survivors $(70.93 \pm 8.48$ vs. $67.75 \pm 10.20$ ), which can also be observed visually in Figure 2. Among these patients, only 11 patients (12\%) had been in close contact with confirmed patients, and no one was ever exposed to the Huanan seafood market. Closer inspection of this table showed that more than half of the patients had underlying health problems, of which the first few were hypertension (60\%), diabetes mellitus (19\%), cardiovascular diseases and chronic pulmonary diseases.

\section{Clinical features on admission}

The clinical features on admission are summarized in Table 2. Interestingly, many laboratory test results were significantly different between the two groups, including WBC, TLC, PLT, CRP, cardiac function indicators, D-dimer, PCT, etc. Low TLC was present in both groups, but it was much lower in nonsurvivors than in survivors $\left(0.63^{*} 10^{9} / \mathrm{L} \pm 0.41\right.$ vs. $\left.0.89 \pm 0.45\right)$. Although the PLT in each group were in the normal range, a lower PLT was observed in nonsurvivors (162.73 \pm 110.55 vs. $203.69 \pm 87.85$ ). The inflammatory indicators, cardiac function, PCT level and D-dimer level in nonsurvivors were more severely impaired than those in survivors as well, while most liver function and kidney function remained normal or mildly abnormal (the influence of underlying health problems cannot be ruled out).

\section{Clinical course}

As a whole, the median duration from admission to transfer to the ICU was 2 days (IQR 0,7$)$, whereas the median length of ICU stay was 8 days (IQR 4,13) (Table 3). The most frequently observed symptom was fever (77\%), followed by dry cough (59\%) and fatigue (54\%). Moreover, few patients developed infrequent conditions, such as headache $(3[3 \%])$, vomiting $(2[\%])$ and diarrhea $(2[2 \%])$. Most patients required supplemental oxygen with nasal high-flow oxygen therapy (71\%); noninvasive mechanical ventilation (54\%) and invasive mechanical ventilation (37\%) were also used in patients, among whom nonsurvivors accounted for a higher proportion and had worse illness. Extracorporeal membrane oxygenation was used in 2 patients; unfortunately, none of them survived. Regarding medications, glucocorticoids ( $80 \%)$, antiviral drugs (79\%) and antibiotics (82\%) were widely used; interestingly, the use of Chinese medicine was statistically significant between the two groups $(P=0.0005)$. Not surprisingly, sepsis $(100 \%)$ and acute respiratory distress syndrome (ARDS) (95\%) were the two most common complications in 
nonsurvivors. Compared to survivors, nonsurvivors also showed a significantly higher proportion of secondary bacterial infection ( $69 \%$ vs. $21 \%$ ), myocardial injury (64\% vs. $15 \%)$, acute kidney injury ( $60 \%$ vs. $13 \%)$, coagulopathy ( $55 \%$ vs. $12 \%$ ) and acute liver injury ( $48 \%$ vs. $12 \%)$.

As shown in Figure 3, the dynamic changes in several key laboratory indexes were compared. It was apparent that TLC and PLT were generally lower in nonsurvivors than in survivors, whereas WBC and CRP levels were higher. We supposed that an elevated WBC was affected by a second bacterial infection and that the usage of glucocorticoids and presence of reduced TLC was expected based on the biological characteristics of this virus. Hepatic enzymes and TBIL were elevated and peaked on approximately the tenth day after admission among nonsurvivors, but the variations were small as a whole. To assess cardiac function, hsTNI was recorded and found to be remarkably increased. CRE and PCT were also recorded (see Figure E1 in the online data supplement).

The distinct trajectories of temperature during the follow-up, which could provide valuable insight to monitoring the recovery of patients, are demonstrated in Figure 4. The patients were classified into 3 groups based on the temperature trajectory after admission as follows: group 1 (stabilized group; $\mathrm{n}=55$, $59.7 \%$ ), maintained a stable temperature below $37^{\circ} \mathrm{C}$; group 2 (down-and-up group; $n=22,24.4 \%$ ), had a mean temperature that decreased at the beginning and finally climbed up; and group 3 (steady-declining group; $\mathrm{n}=15,16.0 \%$ ), the temperature of these patients was initially higher than normal and dropped gradually to approximately $36.4^{\circ} \mathrm{C}$ from the above normal body temperature. Patients with these 3 temperature trajectories had distinct fatalities. Group 1 had the lowest fatality rate at $25.45 \%$, with a mean temperature of $36.46^{\circ} \mathrm{C}$. Patients in group 2 had a mean temperature of $36.71^{\circ} \mathrm{C}$ and a fatality rate of $54.55 \%$. In particular, the steady-declining group was characterized by the highest fatality rate of 93.33\% (mean temperature, $36.98^{\circ} \mathrm{C}$ ). The characteristics at baseline and laboratory tests on admission stratified by temperature trajectory groups were presented in Table E1 (see Table E1 in the online data supplement).

\section{Discussion}

Severe acute respiratory syndrome coronavirus 2 (SARS-CoV-2), which is genetically similar to the severe acute respiratory syndrome (SARS) coronavirus that resulted in the SARS outbreak in 2002, is responsible for a global pandemic of COVID-19. ${ }^{14}$ The outbreak began in China but has since spread around the world. ${ }^{15-17}$ The hospitals and clinics were initially overwhelmed, and both patients and healthcare providers became severely ill and died soon after. However, as the healthcare system response ramped up, more designated and newly built hospitals and better equipment became available, the situation was under control within a short period in China. As usual, different countries have different ways of resolving the conundrum. Although the COVID-19 pandemic is still ongoing, the good news is that in China and South Korea, the number of new cases per day has dropped off, largely due to aggressive public health measures, such as quarantining, aggressive testing, sufficient manpower, and the most importantly, everyone's efforts. ${ }^{18}$ 
In our study, there were 94 confirmed cases of COVID-19 in the ICU of Huoshenshan Hospital, and the 42 deaths resulted in a fatality rate of $45 \%$, which is close to the data reported by the Chinese Centers for Disease Control and Prevention. ${ }^{19}$ As mentioned in the previous literature ${ }^{19}$, approximately $80 \%$ of patients with COVID-19 have mild symptoms, and few people do not develop any symptoms or signs at all. For the remaining $20 \%$, as our study shows, these patients can range from mild symptoms, such as fever and dry cough, all the way to severe conditions, such as ARDS and even sepsis. Based on our data, the rate of critically ill patients is relatively low below the age of 60 , but the rate starts to increase for the elderly. Similarly, both the rate of critical illness and the fatality rate are higher for patients with underlying health problems than for those without any of these conditions. In addition, many elderly patients typically have one or more of these conditions, so it is not surprising that these factors go hand in hand. Unlike seasonal flu, vaccines for SARS-CoV-2 have not yet been well established, although both are respiratory viruses. ${ }^{20}$ Therefore, elderly patients with underlying health problems are truly the ones at highest risk.

The inflammation caused by SARS-CoV-2 builds up much fluid within and around the lung and results in acute respiratory distress syndrome (ARDS) and even subsequent multiple organ dysfunction syndrome, which means that the whole body starts shutting down. ${ }^{21}$ ARDS is a common complication during the clinical course and is the main cause of death. Among the nonsurvivors, all patients were diagnosed with ARDS and sepsis, which is often caused by severe infection. Our experience revealed that ARDS always had sudden onset and rapid development, so few patients died soon. So far, not many treatment options exist for coronavirus, so the only option is offering supportive treatment, such as maintaining respiratory function with oxygen and ventilatory support, while the patient's immune system fights off the virus. In addition, multiple antiviral drugs have been tested, including arbidol hydrochloride, Lianhua Qingwen capsules and broad-spectrum antiviral agents. Some antivirals, such as remdesivir, Actemra, hydroxychloroquine and self-developed vaccines for SARS-CoV-2, are undergoing clinical trials as well, and early data showed that these may be helpful. ${ }^{22}$ However, there are still debates about when and how to use glucocorticoids and whether patients should be incubated. In addition, it can be seen from table 2 that the greatest need is a risk prediction model based on basic data at admission if the sample size is sufficient, since many laboratory indexes are significantly different between survivors and nonsurvivors.

The dynamic changes in these biomarkers raise intriguing questions regarding the nature and extent of targeting of SARS-CoV-2. For example, patients with acute liver injury (26[28\%]) always have obviously increased ALT/AST and TBIL, whereas other hepatic function indexes, such as alkaline phosphatase and gamma-glutamyl transferase, do not change significantly. ${ }^{23}$ Nonetheless, we have reasons to believe that COVID-19-associated liver injury may be affected by various elements, such as hepatotoxic agents and a body-wide inflammatory reaction. ${ }^{13}$ Moreover, other statistically significant biomarkers are a compelling reminder for a poor prognosis.

Temperature trajectories reflect the potential dynamic changing patterns of temperature during the clinical course. This observation provides new insights into COVID-19-associated temperature changes 
and indicates that critical patients with a high temperature should be particularly paid attention to by health care providers, especially those with high temperature on admission.

The strengths of this study include that it is a large retrospective cohort study of critical patients in the ICU with information on COVID-19 and its associated outcomes. It is worth mentioning that early in the disease, a high temperature should receive extra care. On the other hand, our study has several limitations. First, the results of the arterial blood gas analysis, which we believe are quite valuable for prognosis, were incomplete, and some of these data were missing; hence, we did not perform a thorough analysis. Another potential limitation is that we did not analyze the findings of pulmonary imaging, such as chest X-rays and computed tomography. Further studies that take these flaws and unanswered questions into account will need to be undertaken. ${ }^{24}$

\section{Declarations}

\section{ACKNOWLEDEMENTS}

We thank all of the patients, their families and all medical staff involved in this battle against SARS-CoV2.

Author's contributions: WQL, XJZ and HT contributed to the study concept and design. YBR, JXW, WW and $\mathrm{HT}$ collected the original data. $\mathrm{HSH}, \mathrm{YSM}, \mathrm{XWQ}$ and TYS compiled the data. $\mathrm{HSH}, \mathrm{ZCJ}, \mathrm{WW}, \mathrm{HYW}$, WQL, XJZ and HT analyzed and interpreted the data. HSH wrote the draft manuscript. ZCJ and CXZ offered the statistical analyses. WW, JXW and HT revised the manuscript for important intellectual content. WW, HT and HYW obtained the funding. YBR, WW, XJZ, WQL, HT and HYW provided administrative support. XJZ, WQL, HT and HYW supervised the project and gave final approval.

Conflict of Interest Disclosures: There is no competing interest need to be declared.

Funding/Support: This study was supported by National Natural Science Foundation of China (Grant No. $81670015,81722034,81988101,81830054)$, the Ministry of Science and Technology Key Program (Grant No. 2018ZX09101002, 2017ZX100203205), Shanghai Pujiang Program (Grant No. 2019PJD059)

Role of the funding source: The funder of the study had no role in study design, data collection, data analysis, data interpretation, or writing of the paper.

\section{References}

1. Huang $C$, Wang $Y$, Li X, et al. Clinical features of patients infected with 2019 novel coronavirus in Wuhan, China. Lancet. 2020;395(10223):497-506. doi:10.1016/S0140-6736(20)30183-5

2. Guan W-J, Ni Z-Y, Hu Y, et al. Clinical Characteristics of Coronavirus Disease 2019 in China. N Engl J Med. February 2020. doi:10.1056/NEJMoa2002032 
3. National Health Commission of the People's Republic of China. http://www.nhc.gov.cn/. Accessed April 1, 2020.

4. Clinical management of severe acute respiratory infection when novel coronavirus ( $\mathrm{nCoV}$ ) infection is suspected. https://www.who.int/publications-detail/clinical-management-of-severe-acuterespiratory-infection-when-novel-coronavirus-(ncov)-infection-is-suspected. Accessed March 23, 2020.

5. New coronavirus pneumonia prevention and control program (7th ed.). http://www.nhc.gov.cn/yzygj/s7653p/202003/46c9294a7dfe4cef80dc7f5912eb1989.shtml. Accessed March 23, 2020.

6. Chen N, Zhou M, Dong X, et al. Epidemiological and clinical characteristics of 99 cases of 2019 novel coronavirus pneumonia in Wuhan, China: a descriptive study.:7.

7. Wang D, Hu B, Hu C, et al. Clinical Characteristics of 138 Hospitalized Patients With 2019 Novel Coronavirus-Infected Pneumonia in Wuhan, China. 2020:9.

8. Wu C, Chen X, Cai Y, et al. Risk Factors Associated With Acute Respiratory Distress Syndrome and Death in Patients With Coronavirus Disease 2019 Pneumonia in Wuhan, China. 2020:10.

9. Yang X. Clinical course and outcomes of critically ill patients with SARS-CoV-2 pneumonia in Wuhan, China: a single-centered, retrospective, observational study.:7.

10. Zhou F, Yu T, Du R, et al. Clinical course and risk factors for mortality of adult inpatients with COVID19 in Wuhan, China: a retrospective cohort study::9.

11. ARDS Definition Task Force, Ranieri VM, Rubenfeld GD, et al. Acute respiratory distress syndrome: the Berlin Definition. JAMA. 2012;307(23):2526-2533. doi:10.1001/jama.2012.5669

12. Singer M, Deutschman CS, Seymour CW, et al. The Third International Consensus Definitions for Sepsis and Septic Shock (Sepsis-3). JAMA. 2016;315(8):801-810. doi:10.1001/jama.2016.0287

13. Chinese Digestion Association CMDA, Chinese Society of Hepatology CMA. The protocol for prevention, diagnosis and treatment of corona virus infective disease 2019. Chinese Journal of Hepatology. 2020;28(00):E004-E004. doi:10.3760/cma.j.cn501113-20200309-00095

14. Lu R, Zhao X, Li J, et al. Genomic characterisation and epidemiology of 2019 novel coronavirus: implications for virus origins and receptor binding. Lancet. 2020;395(10224):565-574. doi:10.1016/S0140-6736(20)30251-8

15. Livingston E, Bucher K. Coronavirus Disease 2019 (COVID-19) in Italy. JAMA. March 2020. doi:10.1001/jama.2020.4344

16. Day M. Covid-19: surge in cases in Italy and South Korea makes pandemic look more likely. BMJ. 2020;368:m751. doi:10.1136/bmj.m751

17. Holshue ML, DeBolt C, Lindquist S, et al. First Case of 2019 Novel Coronavirus in the United States. N Engl J Med. 2020;382(10):929-936. doi:10.1056/NEJMoa2001191

18. Wu Z, McGoogan JM. Characteristics of and Important Lessons From the Coronavirus Disease 2019 (COVID-19) Outbreak in China: Summary of a Report of 72314 Cases From the Chinese Center for 
Disease Control and Prevention. JAMA. February 2020. doi:10.1001/jama.2020.2648

19. Response EWG for NE, Prevention CC for DC and. The epidemiological characteristics of an outbreak of 2019 novel coronavirus diseases (COVID-19) in China. Chinese Journal of Epidemiology. 2020;41(02):145-151. doi:10.3760/cma.j.issn.0254-6450.2020.02.003

20. Walls AC, Park Y-J, Tortorici MA, Wall A, McGuire AT, Veesler D. Structure, Function, and Antigenicity of the SARS-CoV-2 Spike Glycoprotein. Cell. March 2020. doi:10.1016/j.cell.2020.02.058

21. Xu Z, Shi L, Wang Y, et al. Pathological findings of COVID-19 associated with acute respiratory distress syndrome. Lancet Respir Med. February 2020. doi:10.1016/S2213-2600(20)30076-X

22. Cao B, Wang Y, Wen D, et al. A Trial of Lopinavir-Ritonavir in Adults Hospitalized with Severe Covid19. N Engl J Med. March 2020. doi:10.1056/NEJMoa2001282

23. Chai X, Hu L, Zhang Y, et al. Specific ACE2 Expression in Cholangiocytes May Cause Liver Damage After 2019-nCoV Infection.:13.

24. Callaway E, Cyranoski D. China coronavirus: Six questions scientists are asking. Nature. 2020;577(7792):605-607. doi:10.1038/d41586-020-00166-6

\section{Tables}

Table 1. Baseline characteristics for critical patients with COVID-19

\begin{tabular}{|c|c|c|c|}
\hline & $\begin{array}{l}\text { Overall } \\
(n=94)\end{array}$ & $\begin{array}{c}\text { Non-survivors } \\
(\mathrm{n}=42)\end{array}$ & $\begin{array}{c}\text { Survivor } \\
(n=52)\end{array}$ \\
\hline \multicolumn{4}{|l|}{ Gender, n (\%) } \\
\hline Male & $54(57 \%)$ & $28(67 \%)$ & $26(50 \%)$ \\
\hline Female & $40(43 \%)$ & $14(33 \%)$ & $26(50 \%)$ \\
\hline \multicolumn{4}{|l|}{ Age, n (\%) } \\
\hline $\begin{array}{l}40-49 \\
50-59\end{array}$ & $9(3 \%)$ & $4(10 \%)$ & $\begin{array}{l}3(6 \%) \\
5(10 \%)\end{array}$ \\
\hline $60-69$ & $38(40 \%)$ & $14(33 \%)$ & $24(46 \%)$ \\
\hline $70-79$ & $29(31 \%)$ & $17(40 \%)$ & $12(23 \%)$ \\
\hline 80-89 & $15(16 \%)$ & $7(17 \%)$ & $8(15 \%)$ \\
\hline Mean \pm SD & $69.17 \pm 9.55$ & $70.93 \pm 8.48$ & $67.75 \pm 10.20$ \\
\hline \multicolumn{4}{|l|}{ Exposure history, n (\%) } \\
\hline Exposure to Huanan seafood market & & & \\
\hline Exposure to patients & $11(12 \%)$ & $5(12 \%)$ & $6(12 \%)$ \\
\hline $\begin{array}{l}\text { Long-term residents } \\
\text { undorlving hoalth }\end{array}$ & $83(88 \%)$ & 37 (88\%) & $46(88 \%)$ \\
\hline \multicolumn{4}{|l|}{ Underlying health problems, n (\%) } \\
\hline & $56(60 \%)$ & $25(60 \%)$ & $31(60 \%)$ \\
\hline Chronic bronchitis & $10(11 \%)$ & $5(12 \%)$ & $5(10 \%)$ \\
\hline CAD & $12(13 \%)$ & $9(21 \%)$ & $3(6 \%)$ \\
\hline Cerebral infarction & $7(7 \%)$ & $3(7 \%)$ & $4(8 \%)$ \\
\hline COPD & $5(5 \%)$ & $3(7 \%)$ & $2(4 \%)$ \\
\hline Gout & $4(4 \%)$ & $2(5 \%)$ & $2(4 \%)$ \\
\hline Malignancy & $7(7 \%)$ & $2(5 \%)$ & $5(10 \%)$ \\
\hline Urinary system diseases & $9(10 \%)$ & $4(10 \%)$ & $5(14 \%)$ \\
\hline Digestive system diseases & $6(6 \%)$ & $4(10 \%)$ & $2(4 \%)$ \\
\hline Smoking & $6(6 \%)$ & $4(10 \%)$ & $2(4 \%)$ \\
\hline Alcohol consumption & & & $1(2 \%)$ \\
\hline
\end{tabular}

Abbreviation: CAD, Coronary artery disease COPD, Chronic obstructive pulmonary disease 
Table 2. Basic data of vital signs on admission and laboratory tests before treatments 


\begin{tabular}{|c|c|c|c|}
\hline \multirow{2}{*}{\multicolumn{4}{|c|}{ Vital signs }} \\
\hline & & & \\
\hline $\mathrm{T},{ }^{\circ} \mathrm{C}$ & $37.08 \pm 0.85$ & $36.70 \pm 0.61$ & $0.0140^{*}$ \\
\hline $\mathrm{SBP}, \mathrm{mmHg}$ & $135.02 \pm 18.82$ & $135.83 \pm 20.43$ & 0.8449 \\
\hline DBP, mmHg & $79.50 \pm 16.98$ & $81.81 \pm 16.01$ & 0.5005 \\
\hline $\mathrm{RR}, \mathrm{n}$ & $22(20,25)$ & $21.5(19,24.5)$ & 0.1827 \\
\hline $\mathrm{P}, \mathrm{n}$ & $90.50(84,104)$ & $85(75.50,94.50)$ & $0.0153^{*}$ \\
\hline \multicolumn{4}{|l|}{ Laboratory Tests } \\
\hline \multicolumn{4}{|l|}{ Complete Blood Cell } \\
\hline WBC, $* 10^{\wedge} 9 / \mathrm{L}$ & $12.70 \pm 8.40$ & $9.79 \pm 6.11$ & 0.0949 \\
\hline Neutrophil ratio, \% & $87.82 \pm 8.98$ & $82.04 \pm 9.53$ & $0.0018^{*}$ \\
\hline Lymphocyte ratio, \% & $6.88 \pm 6.38$ & $11.45 \pm 6.86$ & $0.0002^{*}$ \\
\hline $\mathrm{TLC}, * 10^{\wedge} 9 / \mathrm{L}$ & $0.63 \pm 0.41$ & $0.89 \pm 0.45$ & $0.0027^{*}$ \\
\hline $\mathrm{RBC}, * 10^{\wedge} 12 / \mathrm{L}$ & $3.78 \pm 0.79$ & $3.85 \pm 0.78$ & 0.8071 \\
\hline $\mathrm{HGB}, \mathrm{g} / \mathrm{L}$ & $116.03 \pm 22.05$ & $116.90 \pm 23.64$ & 1.0000 \\
\hline $\mathrm{PLT}, * 10^{\wedge} 12 / \mathrm{L}$ & $162.73 \pm 110.55$ & $203.69 \pm 97.85$ & $0.0208^{*}$ \\
\hline \multicolumn{4}{|l|}{ Inflammatory Indicators } \\
\hline $\mathrm{CRP}, \mathrm{mg} / \mathrm{L}$ & $101.56 \pm 78.28$ & $50.09 \pm 48.14$ & $0.0010^{*}$ \\
\hline Ultra-sensitive CRP, mg/L & $13.00 \pm 19.81$ & $8.99 \pm 6.61$ & $0.0094^{*}$ \\
\hline \multicolumn{4}{|l|}{ Liver Function } \\
\hline $\begin{array}{l}\text { ALT, IU/L } \\
\text { AST, IU/L }\end{array}$ & $\begin{array}{l}41.64 \pm 36.41 \\
50.04 \pm 40.84\end{array}$ & $\begin{array}{l}50.82 \pm 46.64 \\
36.51 \pm 32.28\end{array}$ & 0.3875 \\
\hline Albumin, g/L & $31.29 \pm 4.63$ & $31.91 \pm 3.61$ & 0.3580 \\
\hline TBIL, $\mu \mathrm{mol} / \mathrm{L}$ & $15.77 \pm 10.98$ & $10.16 \pm 4.83$ & $0.0009^{*}$ \\
\hline IBIL, $\mu \mathrm{mol} / \mathrm{L}$ & $7.82 \pm 5.94$ & $6.19 \pm 2.51$ & 0.4140 \\
\hline ALP, IUU/L & $105.79 \pm 47.88$ & $90.22 \pm 57.98$ & $0.0094^{*}$ \\
\hline GGT, IU/L & $63.54 \pm 46.93$ & $71.30 \pm 83.84$ & 0.7985 \\
\hline \multicolumn{4}{|l|}{ Kidney Function } \\
\hline GLU, $\mathrm{mmol} / \mathrm{L}$ & $9.24 \pm 3.90$ & $7.14 \pm 3.28$ & $0.0007^{*}$ \\
\hline UREA, mmol/L & $10.73 \pm 8.09$ & $7.84 \pm 7.18$ & $0.0149^{*}$ \\
\hline $\mathrm{CRE}, \mathrm{mmol} / \mathrm{L}$ & $103.70 \pm 97.44$ & $101.4 \pm 172.46$ & $0.0005^{*}$ \\
\hline $\mathrm{UA}, \mathrm{mmol} / \mathrm{L}$ & $283.29 \pm 177.37$ & $229.19 \pm 142.65$ & 0.0751 \\
\hline \multicolumn{4}{|l|}{ Electrolytes } \\
\hline $\mathrm{K}^{+}, \mathrm{mmol} / \mathrm{L}$ & $4.57 \pm 0.86$ & $4.27 \pm 0.74$ & $0.0415^{*}$ \\
\hline $\mathrm{Na}^{+}, \mathrm{mmol} / \mathrm{L}$ & $143.74 \pm 8.99$ & $140.08 \pm 4.52$ & 0.0713 \\
\hline $\mathrm{Cl}^{-}, \mathrm{mmol} / \mathrm{L}$ & $106.22 \pm 8.08$ & $103.64 \pm 5.12$ & 0.1797 \\
\hline $\mathrm{Ca}^{2+}, \mathrm{mmol} / \mathrm{L}$ & $1.95 \pm 0.13$ & $2.05 \pm 0.14$ & $0.0013^{*}$ \\
\hline \multicolumn{4}{|l|}{ Cardiac function } \\
\hline CK-MB, IU/L & $25.06 \pm 21.43$ & $14.15 \pm 11.37$ & $0.0003^{*}$ \\
\hline LDH, IU/L & $517.51 \pm 216.17$ & $317.46 \pm 172.94$ & $<0.0001^{*}$ \\
\hline $\mathrm{BNP}, \mathrm{pg} / \mathrm{ml}$ & $239.64 \pm 303.73$ & $162.54 \pm 280.22$ & $0.0144^{*}$ \\
\hline hsTNI, ng/ml & $1.00 \pm 2.45$ & $0.04 \pm 0.08$ & $<0.0001^{*}$ \\
\hline \multicolumn{4}{|l|}{ Coagulation function } \\
\hline $\mathrm{PT}, \mathrm{s}$ & $16.60 \pm 3.53$ & $15.00 \pm 6.65$ & $<0.0001^{*}$ \\
\hline $\mathrm{INR}, \mathrm{n}$ & $1.38 \pm 0.29$ & $1.23 \pm 0.54$ & $<0.0001^{*}$ \\
\hline $\begin{array}{l}\text { APTT, s } \\
\text { FIB, g/L }\end{array}$ & $\begin{array}{c}29.46 \pm 6.22 \\
3.17 \pm 1.17\end{array}$ & $\begin{array}{c}28.38 \pm 7.64 \\
3.88 \pm 2.40\end{array}$ & $\begin{array}{l}0.9468 \\
0.1103\end{array}$ \\
\hline D-dimer mg/L & $6.9 \pm 5.89$ & $2.68 \pm 2.77$ & $<0.0001^{*}$ \\
\hline $\mathrm{PCT}, \mathrm{ng} / \mathrm{ml}$ & $1.61 \pm 3.76$ & $0.32 \pm 0.78$ & $0.0001^{*}$ \\
\hline
\end{tabular}

Data presented as Mean \pm SD or Median (Q1, Q3) 
Abbreviation: T, Temperature; SBP, Systolic blood pressure; DBP, Diastolic blood pressure; WBC, RR, Respiratory rate; P, Pulse; WBC, White blood cell count; TLC, Total lymphocyte count; RBC, Red blood cell count; HBG, Hemoglobin; PLT, Platelet; CRP, C-reactive protein; ALT, Alanine transaminase; AST, Aspartate transaminase; TBIL, Total bilirubin; IBIL, Indirect bilirubin; ALP, Alkaline phosphatase; GGT, Gamma-glutamyl transferase; GLU, Glucose; CRE, Creatinine; UA, Uric acid; CK-MB, Creatine kinase-MB; LDH, Lactate dehydrogenase; BNP, B-type natriuretic peptide; hsTNI, hypersensitive troponin I; PT, Prothrombin; INR, International Normalized Ratio; APTT, Activated partial thromboplastin time; FIB, Fibrinogen; PCT, Procalcitonin

$* \mathrm{P}<0.05$ for comparison with survivor and non-survivor

Table 3. Clinical manifestation, including symptoms, complications and treatments of these patients 


\begin{tabular}{|c|c|c|c|c|}
\hline & $\begin{array}{l}\text { Overall } \\
(\mathrm{n}=94)\end{array}$ & $\begin{array}{c}\text { Non- } \\
\text { survivors } \\
(\mathrm{n}=42)\end{array}$ & $\begin{array}{l}\text { Survivor } \\
(\mathrm{n}=52)\end{array}$ & P-value \\
\hline \multicolumn{5}{|l|}{ Symptoms, n (\%) } \\
\hline Fever & $71(77)$ & $33(80)$ & $39(76)$ & 0.6424 \\
\hline Dry cough & $55(59)$ & $24(59)$ & $31(61)$ & 0.8270 \\
\hline Fatigue & $51(54)$ & $24(29)$ & $27(53)$ & 0.5915 \\
\hline Myalgia & $27(29)$ & $12(29)$ & $15(30)$ & 0.9394 \\
\hline Breathlessness & $26(28)$ & $11(27)$ & $15(30)$ & 0.7845 \\
\hline Chest tightness & $14(15)$ & $5(12)$ & $9(18)$ & 0.4693 \\
\hline Headache & $3(3)$ & $1(2)$ & $2(4)$ & 1.0000 \\
\hline Vomiting & $2(2)$ & $1(2)$ & $1(2)$ & 1.0000 \\
\hline Diarrhea & $2(2)$ & $1(2)$ & $1(2)$ & 1.0000 \\
\hline Asymptom & $3(3)$ & $2(5)$ & $1(2)$ & 0.4363 \\
\hline Time of transfer to ICU, median (Q1, & $2(0,7)$ & $3(1,7)$ & $0(0,6.5)$ & 0.0630 \\
\hline Time of ICU stay, median (Q1, Q3) & $8(4$ & $7(3,13)$ & $9(5.5$, & 0.2149 \\
\hline \multicolumn{5}{|l|}{ Complication, n (\%) } \\
\hline Sepsis & $76(81)$ & $42(100)$ & $34(65)$ & $<0.0001^{*}$ \\
\hline ARDS & $68(72)$ & $40(95)$ & $28(48)$ & $<0.0001^{*}$ \\
\hline Secondary bacterial infection & $40(43)$ & $29(69)$ & $11(21)$ & $<0.0001^{*}$ \\
\hline Myocardial injury & $35(37)$ & $27(64)$ & $8(15)$ & $<0.0001^{*}$ \\
\hline AKI & $32(34)$ & $25(60)$ & $7(13)$ & $<0.0001^{*}$ \\
\hline Coagulopathy & $29(31)$ & $23(55)$ & $6(12)$ & $<0.0001^{*}$ \\
\hline Acute liver injury & $26(28)$ & $20(48)$ & $6(12)$ & $0.0001^{*}$ \\
\hline Gastrointestinal hemorrhage & $8(9)$ & $5(12)$ & $3(6)$ & 0.4914 \\
\hline \multicolumn{5}{|l|}{ Treatments } \\
\hline $\begin{array}{l}\text { Nasal high-flow oxygen therapy } \\
\text { Non-invasive ventilation }\end{array}$ & $67(71)$ & $38(90)$ & $29(56)$ & 0.0002 \\
\hline $\begin{array}{l}\text { Non-invasive ventilation } \\
\text { Invasive ventilation }\end{array}$ & $51(54)$ & $\begin{array}{l}39(93) \\
33(79)\end{array}$ & $12(23)$ & $<0.0001^{*}$ \\
\hline $\begin{array}{l}\text { Invasive ventilation } \\
\text { ECMO }\end{array}$ & $35(37)$ & $33(79)$ & $2(4)$ & $<0.0001^{*}$ \\
\hline $\begin{array}{l}\text { ECMO } \\
\text { Glucocorticoids } \\
\text { Antiviral drugs }\end{array}$ & $\begin{aligned} 2 & (2) \\
75 & (80)\end{aligned}$ & $\begin{aligned} 2 & (5) \\
36 & (86)\end{aligned}$ & $39 \stackrel{0}{(75)}$ & $\begin{array}{l}0.1970 \\
0.1984\end{array}$ \\
\hline $\begin{array}{l}\text { Antiviral arugs } \\
\text { Arbidol hydrochloride }\end{array}$ & $52(55)$ & $26(62)$ & $26(50)$ & 0.2484 \\
\hline Lianhua Qingwen Capsule & $33(35)$ & $16(38)$ & $17(33)$ & 0.5853 \\
\hline Chinese medicine & 31 (33) & $6(14)$ & $25(48)$ & $0.0005^{*}$ \\
\hline Interferon & $3(3)$ & $1(2)$ & $2(4)$ & 1.0000 \\
\hline Oseltamivir & $6(6)$ & $2(5)$ & $4(8)$ & 0.8780 \\
\hline Ribavirin & $8(9)$ & $4(10)$ & $4(8)$ & 1.0000 \\
\hline Antibiotics & $77(82)$ & 39 (93) & $38(73)$ & $0.0132^{*}$ \\
\hline Immunoglobulin & $35(37)$ & $16(38)$ & $19(37)$ & 0.8766 \\
\hline Vasoconstrictor & $40(43)$ & $38(90)$ & $2(4)$ & $<0.0001^{*}$ \\
\hline Proton pump inhibitor & $59(63)$ & $28(67)$ & $31(60)$ & 0.4820 \\
\hline Renal replacement therapy & $15(16)$ & $13(31)$ & $2(4)$ & $0.0004^{*}$ \\
\hline
\end{tabular}

Abbreviation: ARDS, acute respiratory distress syndrome AKI, acute kidney injury ECMO, Extracorporeal membrane oxygenation

$* \mathrm{P}<0.05$ for comparison with survivor and non-survivor

\section{Figures}




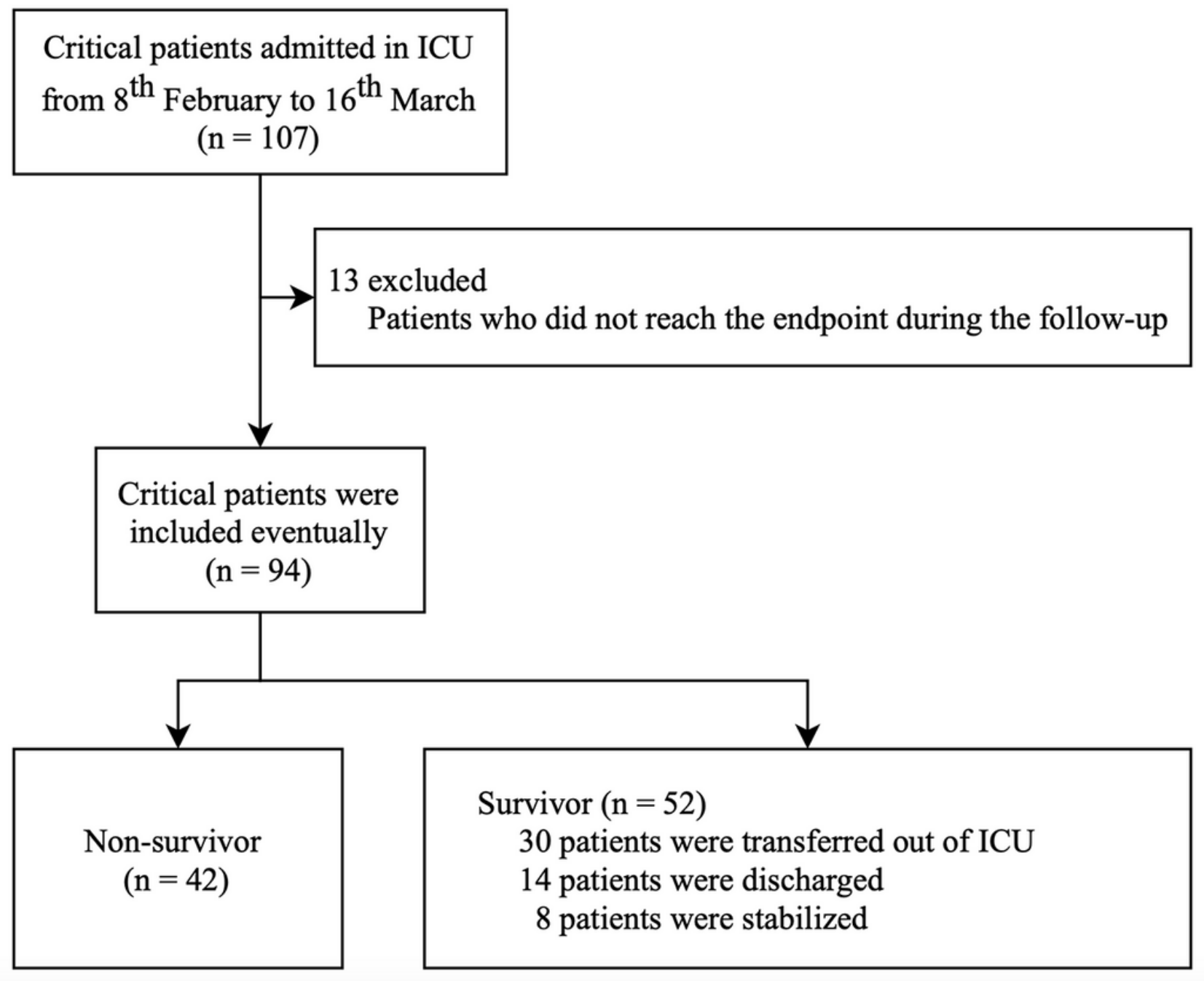

Figure 1

Flow chart of patient inclusion 


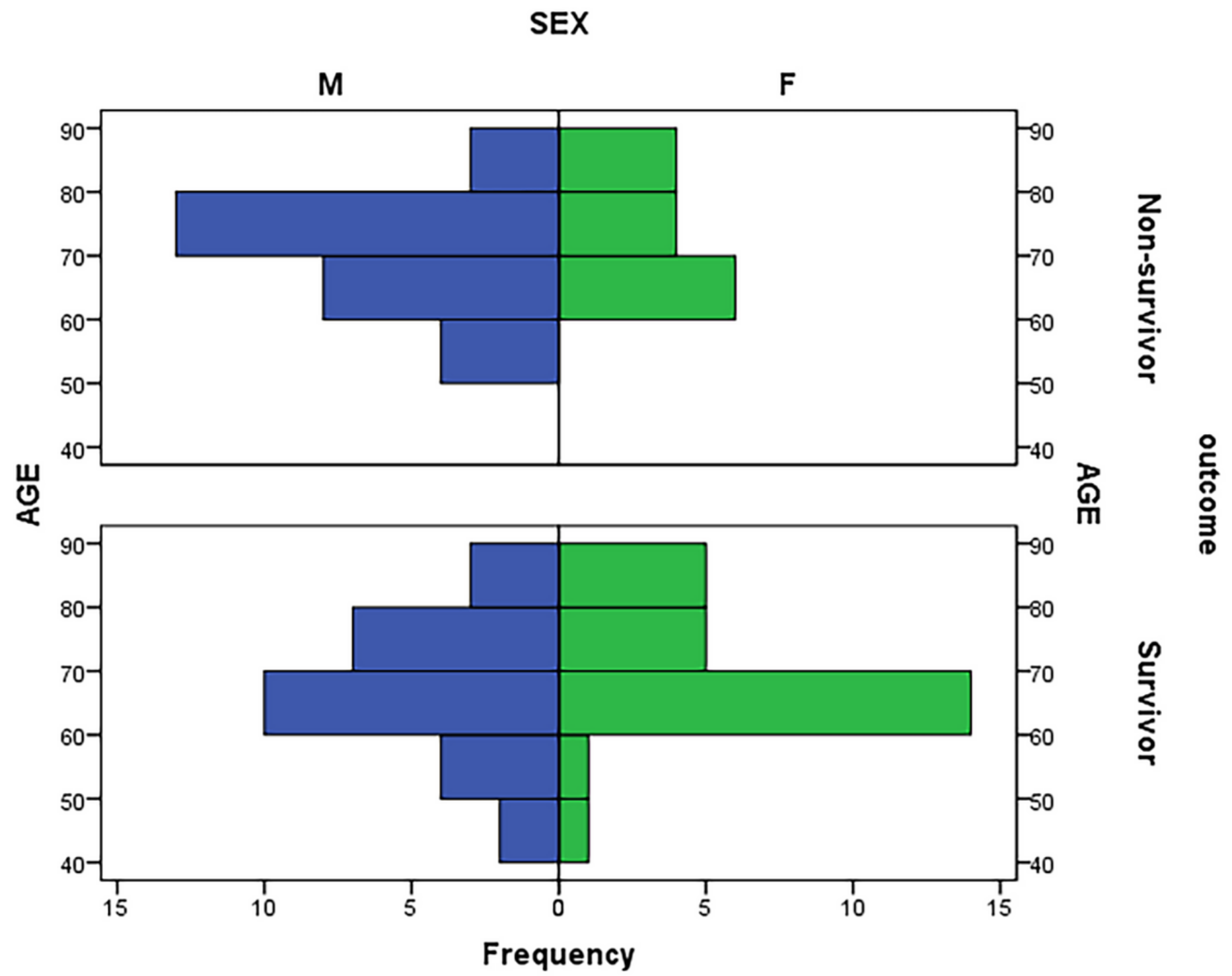

Figure 2

Population pyramid of included patients 

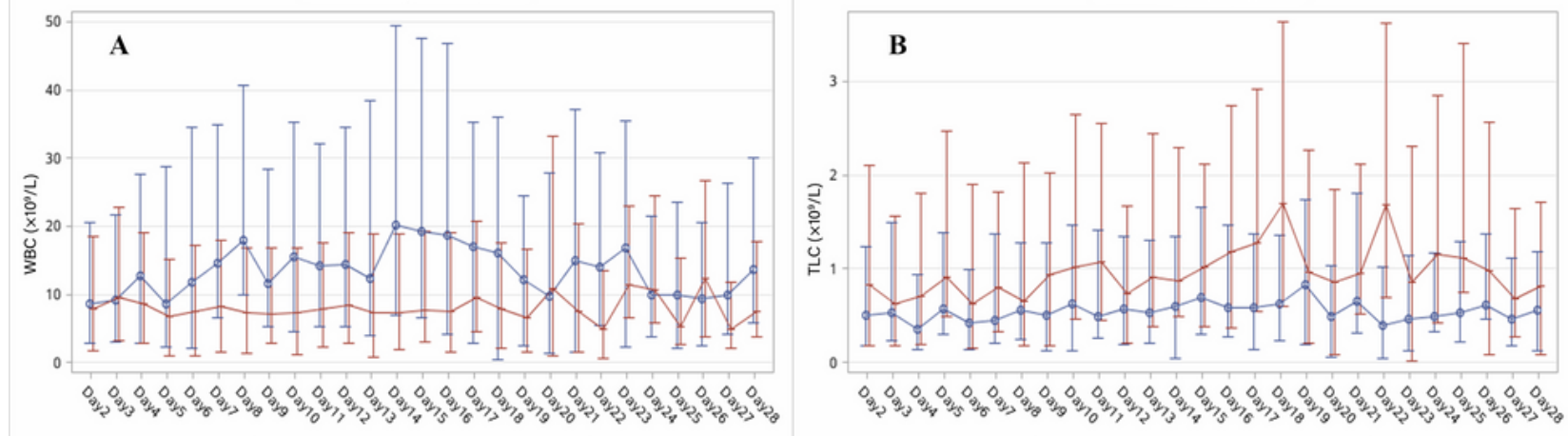

Oulcome $\longrightarrow$ Non-survivar $\longrightarrow$ Survive

Outcome $\rightarrow-$ Non-sunvivor $\longrightarrow$ Survivor
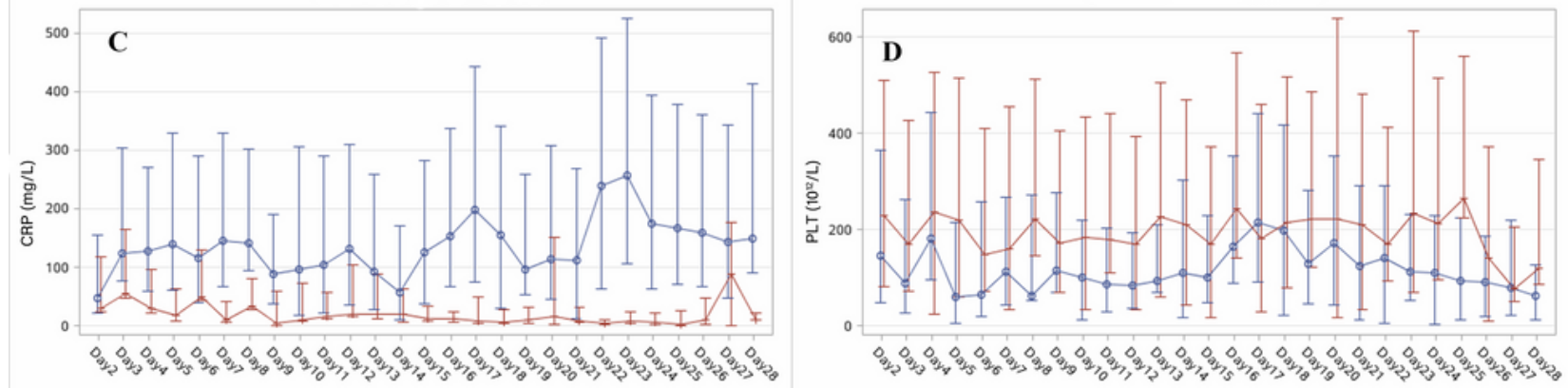

Outcome $\longrightarrow$ - Non-sunvivor $\longrightarrow$ - Survivor

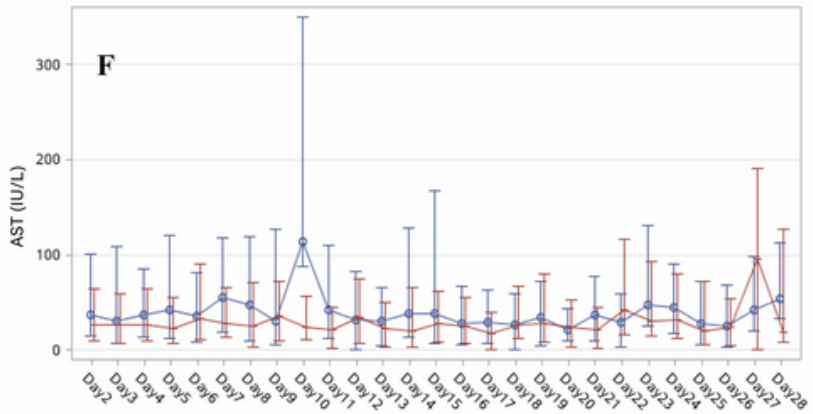

Outcome -0 Non-survivor $\longrightarrow$ Survivor
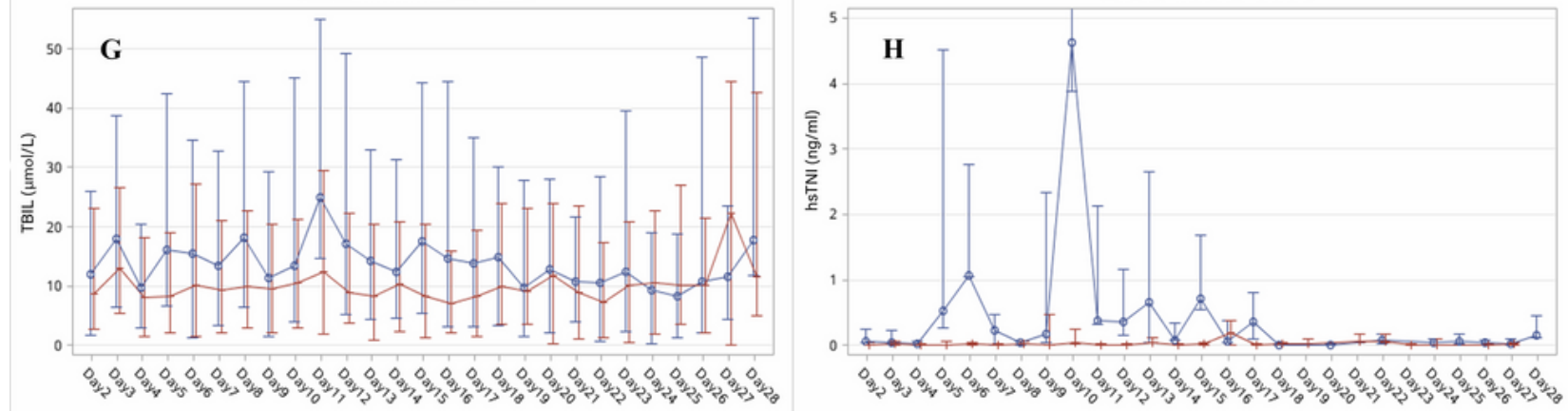

Outcome -0 Non-sunvivor $\longrightarrow$ Sunvivor

\section{Figure 3}

Dynamic changes of several important laboratory indexes during the follow-up period. (A) White blood cell (WBC) counts; (B) Lymphocyte; (C) C-reactive protein; (D) Platelet; (E) Alanine transaminase (ALT); (F) Aspartate transaminase (AST); (G) Total bilirubin (TBIL); (H) Hypersensitive troponin I (hsTNI) 


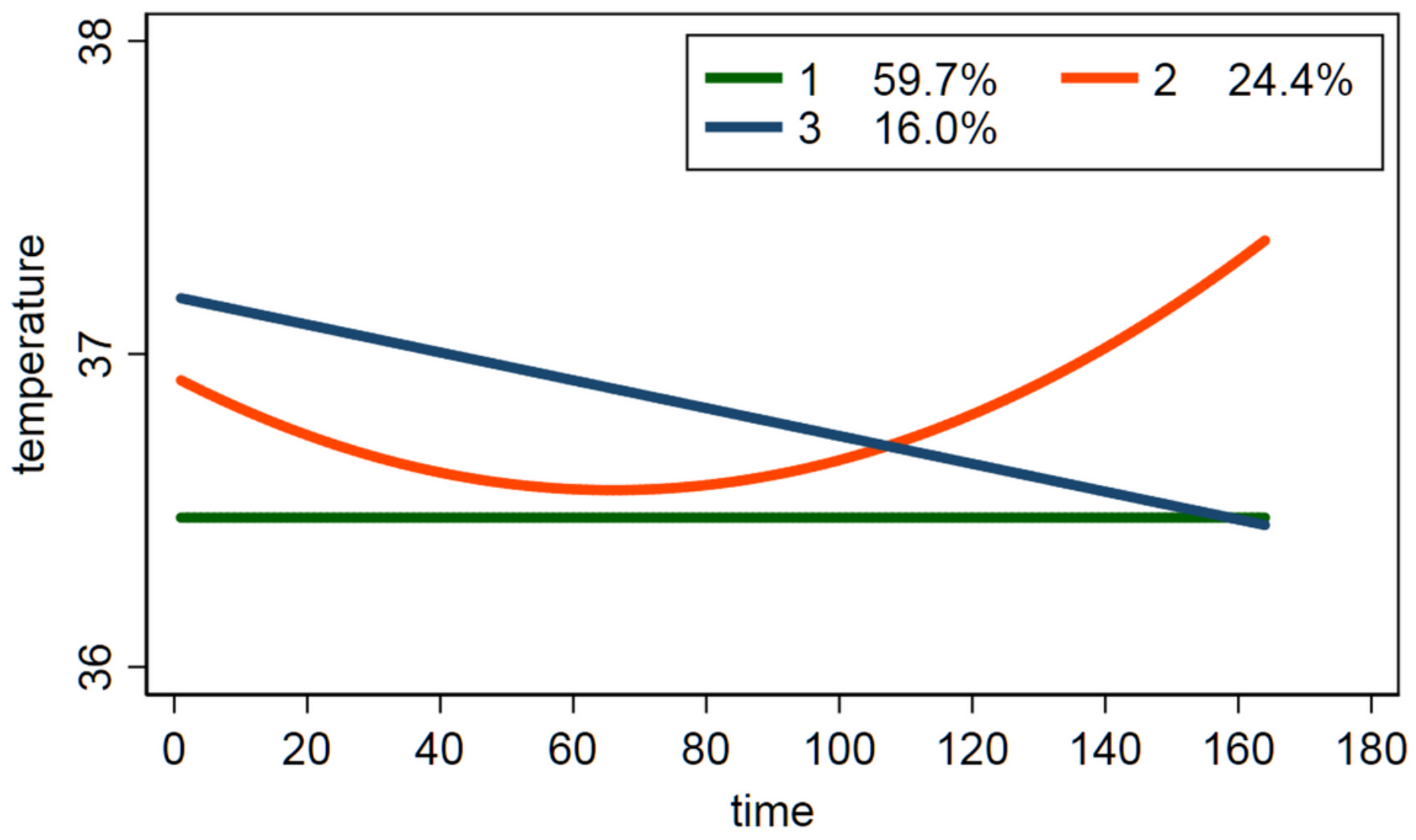

Figure 4

Trajectories of temperature for patients from admission to 16th March. Group 1 (a stabilized group; $\mathrm{n}=55$, $59.7 \%$ ); Group 2 (a down-and-up group; $n=22,24.4 \%$ ); Group 3 (a steady-declining group; $n=15,16.0 \%$ )

\section{Supplementary Files}

This is a list of supplementary files associated with this preprint. Click to download.

- OnlineDataSupplement.docx

- FigureE1.png 